\title{
Correction to: MineCap: super incremental learning for detecting and blocking cryptocurrency mining on software-defined networking
}

\author{
Helio N. Cunha Neto ${ }^{1}$ (D) $\cdot$ Martin Andreoni Lopez ${ }^{2} \cdot$ Natalia C. Fernandes $^{1} \cdot$ Diogo M. F. Mattos $^{1}$
}

Published online: 29 January 2020

(C) Institut Mines-Télécom and Springer Nature Switzerland AG 2020

\section{Correction to: Annals of Telecommunications} https://doi.org/10.1007/s12243-019-00744-4

The funding information in the original manuscript is incorrect, the correct information should be the below:

Funding information We would like to acknowledge CNPq, CAPES, FAPERJ, RNP, Taesa, and the ANEEL's R\&D program (PD-07130-0053/ 2018) for the partial funding of this research.

Publisher's note Springer Nature remains neutral with regard to jurisdictional claims in published maps and institutional affiliations.

The online version of the original article can be found at https://doi.org/ 10.1007/s12243-019-00744-4

Helio N. Cunha Neto

heliocunha@midiacom.uff.br

Martin Andreoni Lopez

m.andreoni@samsung.com

Natalia C. Fernandes

natalia@midiacom.uff.br

Diogo M. F. Mattos

menezes@midiacom.uff.br

1 Midiacom/PPGEET/TET, Universidade Federal Fluminense (UFF), Niterói, RJ, Brazil

2 Samsung Research Institute, Campinas, SP, Brazil 